Revista Latinoamericana de la Papa 23 (1): 63 - 75, 2019

ISSN: 1853-4961

http://ojs.papaslatinas.org/index.php/rev-alap/index

\title{
Qué está pasando con el clima y el tizón de la papa [Phytophthora infestans (Mont.) De Bary] en Bolivia
}

\author{
J. Gabrieli; B. Condori ${ }^{2 / *}$; A. Gandarillas ${ }^{3}$; G. Plata ${ }^{3}$
}

Recibido: $21 / 04 / 2019$

Aceptado: $31 / 05 / 2019$

Accesible en línea: Junio de 2019

\section{Resumen}

En este documento de reflexión se hace referencia a la literatura disponible en Bolivia y otros países sobre los avances en el conocimiento y el control del tizón tardío de la papa (Phytophthora infestans) como agente causal de una temida enfermedad que afecta al cultivo de papa, que a lo largo de muchos años causó grandes pérdidas en diferentes partes del mundo. En el mismo se analiza los avances del conocimiento del patógeno y el desarrollo del manejo integrado de la enfermedad a través de estrategias químicas y el uso de cultivares resistentes con potencial de alto rendimiento; así mismo, se analiza las implicaciones del tizón en el futuro por el efecto del cambio climático y el cambio de las épocas de siembra del cultivo. Finalmente se hace algunas consideraciones de manejo integrado para afrontar este problema que causa grandes pérdidas a los agricultores pobres de la zona andina e interandina de Bolivia.

Palabras clave adicionales: Pérdidas, cultivares, razas, virulencia, patógeno.

\section{What is happening with climate and potato late blight [Phytophthora infestans (Mont.) De Bary] in Bolivia \\ Summary}

In this reflection document, reference is made to the literature available in Bolivia and other countries on advances in knowledge and control of late blight of potato (Phytophthora infestans) as the causal agent of a feared disease that affects potato cultivation, that for many years caused great losses in different parts of the world. In it advances in knowledge of the pathogen and the development of integrated disease management are analyzed through chemical strategies and the use of resistant cultivars with high yield potential; likewise, the implications of late blight are analyzed by the effect of climate change and the change of the sowing seasons of the crop. Finally, some considerations of integrated management are made to face this problem that causes great losses to the poor farmers of the Andean and inter-Andean area of Bolivia.

Additional keywords: Losses, cultivars, breeds, virulence, pathogen.

\footnotetext{
Autor para correspondencia: bcondori@yahoo.com

Fundación PROINPA, Bolivia. Actualmente Universidad Estatal del Sur de Manabí, Jipijapa, Manabí, Ecuador. E-mail: julio.gabriel@unesum.edu.org

2 Universidad Mayor de San Andrés, Facultad de Agronomía. La Paz, Bolivia.

3 Fundación PROINPA, Casilla 4285, Cochabamba, Bolivia.
} 


\section{Introducción}

El tizón [Phytophthora infestans (Mont.) De Bary], Llejte ó Llejti en aimará y T'octu ó Jauch'a en quechua es una de las enfermedades más devastadoras de la papa a nivel mundial. En Bolivia, el tizón es la enfermedad más importante de las zonas húmedas, afectando a unas $20 \mathrm{mil}$ hectáreas de producción de papa, de las cuales una gran parte se halla dedicada a la producción de semilla. El tizón tardío, compromete la economía de cerca de 40 mil familias de agricultores (Gandarillas y Ortuño, 2009). En estas zonas el tizón puede devastar los cultivos de papa en dos a tres días y las pérdidas pueden llegar hasta un $100 \%$ debido al desconocimiento de estrategias adecuadas de control químico por parte de los agricultores (Navia et al., 2009).

Para el control del tizón se utiliza una gama amplia de fungicidas sistémicos y de contacto, aplicados con bombas de mochila en un $30 \%$ por debajo de la dosis recomendada y entre dos a 10 oportunidades, generalmente no se realiza una buena cobertura de las plantas asperjadas y los intervalos entre las aplicaciones son largos. Generalmente los agricultores hacen 16 aplicaciones en zonas muy tizoneras. En algunos casos se utilizan mezclas de dos o más fungicidas sistémicos (los denominados combos) o solo sistémicos en un elevado número de aplicaciones. Como consecuencia el ataque del tizón es severo y comúnmente las parcelas son abandonadas (Navia et al., 2009).

El tizón ataca a la papa en cualquier fase de desarrollo del cultivo, afectando las hojas tallos, bayas y tubérculos. Los primeros síntomas se inician frecuentemente en los brotes de las hojas, presentándose a manera de pequeñas manchas de color verde claro a oscuro que se convierten en lesiones de color marrón de aspecto humedecido en caso de que las condiciones sean favorables, su avance es muy rápido afectando a la totalidad del follaje. Algunas veces se presenta un halo de color verde claro a amarillo alrededor de la lesión (CocaMorante, 2012).

En condiciones de alta humedad, se hace visible una esporulación (vellosidad) blanquecina, especialmente en la cara inferior de la hoja. Estas son las estructuras del patógeno: esporangióforos y esporangios. Los esporangios son diseminados por el viento y el agua de la lluvia haciendo que la enfermedad se propague rápidamente desde los primeros foliolos infectados, hasta todas las hojas y así a todas las plantas de una parcela, causando la muerte de las mismas en pocos días (Coca-Morante, 2012).

Los tallos y peciolos presentan manchas necróticas alargadas de color café oscuro, tomando una consistencia vítrea que puede quebrarse fácilmente por acción del viento, de aquí el nombre quechua de p'aki-p'aki (quebradizo). Los tubérculos son infectados por esporangios que la lluvia lava de las hojas y del tallo penetrando en el suelo hasta llegar a los mismos, esta infección los agricultores la denominan como k'anura en quechua. La superficie de los tubérculos afectados presenta áreas irregulares ligeramente hundidas de color café oscuro y de apariencia húmeda. Partiendo el tubérculo se observa una pudrición corchosa de color café claro a oscuro debajo de la piel y hacia el interior del tubérculo. Los tubérculos infectados son la principal fuente de inóculo para la siguiente campaña agrícola (Navia et al., 2009). 


\section{Distribución del tizón en Bolivia}

El tizón tiene una gran capacidad de diseminación, invernando en forma de micelio en los tubérculos de papa infectados, este micelio se propaga en los tejidos de estos tubérculos y alcanza los nuevos brotes iniciando la diseminación a otras plantas. De la misma manera, se puede iniciar la diseminación de plantas voluntarias o k'ipas desarrolladas a partir de tubérculos enfermos, o de papas que fueron depositadas en montones de desechos.

El tizón está distribuido ampliamente en las zonas productoras de papa (Figura 1), desde el norte hasta el sur del lado Este de la cordillera Oriental de los Andes (Fernández Northcote et al., 1999; Navia et al., 1999; Coca-Morante, 2012; CocaMorante y Tolin-Tordoya, 2013). De acuerdo a estos estudios, el tizón está presente entre los 2800 a $3500 \mathrm{msnm}$, aunque la presencia del patógeno puede estar en zonas más bajas y altas a estos rangos. En Bolivia, las zonas de incidencia del tizón están ubicadas en las comunidades de: Morochata, El Choro,
Falsuri, Cocapata. Independencia, Colomi. Candelaria, Corani, Chullchungani, Monte Punku, Lope Mendoza, Epizana, Escalante, Tiraque, Arani, Capinota, Valle Alto, Valle Bajo y Mizque en el departamento de Cochabamba; Comarapa, Los Pinos, Verdecillos, San Isidro, Saipina, Rio Nuevo, Los Negros, San Pedro, San Marcos y Valle Grande en el departamento de Santa Cruz; San Andrés, La Huerta Concepción, Iscayachi, Pilaya, Entre Ríos en el departamento de Tarija; Tacacoma. Sorata, Inquisivi, Mohoza, Irupana, Coroico, Charazani, Chullna, Puerto Acosta, Amarette, y Moyapampa en el departamento de La Paz; La Cordillera de El Rosal, Culpina, Incahuasi en el departamento de Chuquisaca; y en las partes bajas de los Departamentos de Potosí y Oruro (Fernández Northcote et al., 1999; Gandarillas y Ortuño, 2009; Coca-Morante, 2012; Coca-Morante y Tolin -Tordoya, 2013; Gabriel et al., 2013). Las localidades mencionadas arriba fueron cartografiadas en un sistema SIG en base a su latitud y longitud geográfica presentada en la Figura 1. 


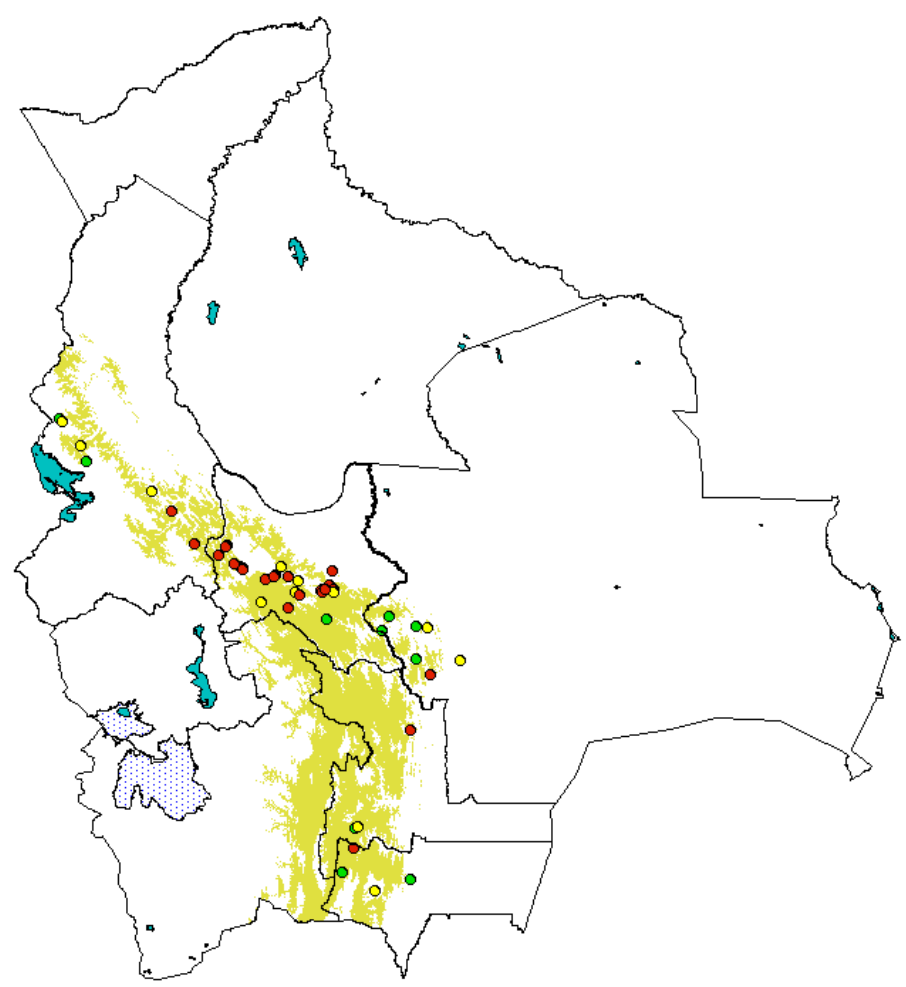

Figura 1. Distribución de P. infestans en Bolivia. Elaboración propia.

El levantamiento de muestras $(n=51)$ analizadas en campo y laboratorio identificaron las zonas muy tizoneras (círculos rojos), zonas no muy tizoneras (círculos verdes) y zonas intermedias entre ambas (círculos amarillos) (Figura 1). Estos sitios se distribuyen a lo largo de la zona productora de papa en Bolivia que va según altimetría del mapa desde los 1188 hasta los 3966 msnm (área en café claro) (Elaborado por el Dr. Bruno Condori).

De acuerdo a los estudios hallados sobre presencia de tizón en Bolivia, éstos se hallan distribuidos a lo largo de las zonas de producción de papa, donde según su patogenicidad se clasifican en dos principales: las zonas muy tizoneras, que tienen clima muy propicio para el desarrollo del patógeno con temperaturas más cálidas, además de intensas precipitaciones, por ello en ésta zona el ataque del patógeno suele presentarse desde tempranas etapas del ciclo agrícola cuando las plantas aún son pequeñas; en las zonas no muy tizoneras, no es frecuente la aparición del tizón en etapas tempranas del ciclo agrícola, debido a condiciones de temperaturas promedio más frías y una precipitación menos intensa que en la otra zona, reduciendo así las probabilidades del ataque del tizón (Navia et al., 2009).

\section{Biología y epidemiología del tizón tardio en relación al clima}

El género Phytophthora pertenece a la clase Oomycetes, phylium Oomycota, reino Cromista. Este fitopatógeno cuyo 
nombre en griego significa destructor de plantas fue en un principio clasificado como hongo debido a sus formas filamentosas parecidas a hifas, hasta que el análisis de las secuencias del rADN y la composición de su pared celular lo relacionaron más estrechamente con las algas pardas y las diatomeas que con los hongos (Pérez y Forbes, 2008; Nieva, 2012). Además, a diferencia de los hongos verdaderos, los Oomycetes presentan meiosis en los gametangios, siendo sus núcleos vegetativos de naturaleza diploide.

Los miembros del género Phytophthora son organismos heterocontes caracterizados por tener zoosporas propulsadas por flagelos de longitud y morfología variable, un micelio de hifas cenocíticas ( $\sin$ septas), y la pared celular compuesta por celulosa. $P$. infestans, tiene dos grupos de compatibilidad sexual (GC): A1 y A2 (Nieva, 2012). En Bolivia, los estudios realizados demostraron que las poblaciones de $P$. infestans son del tipo de apareamiento sexual A2 y, se asumió la inexistencia del apareamiento A1 (Plata, 1988), por lo que se la consideraba como una población asexual.

Basándose en la reacción en cadena de la polimerasa (PCR), Judelson et al. (1996), desarrolló unos iniciadores específicos capaces de amplificar un fragmento de 1400 pb del locus S1 presente únicamente en los aislados tipo A1, y ausente en los aislamientos del tipo A2. Los mismos autores diseñaron también marcadores moleculares CAPs (Cleaved Amplified Polymorphic Sequence) capaces de amplificar el mismo fragmento de ADN en aislados del tipo A1 y A2, pero que tras la digestión con una endonuclueasa de restricción permite diferenciar ambos grupos por presentar variación en la longitud de los fragmentos generados. Estos marcadores fueron usados por investigadores de Bolivia, reportando que las poblaciones de tizón son más bien perteneciente al tipo de apareamiento A1 (Gabriel et al., 2018), esto es un nuevo paradigma y pone en duda la no existencia del tipo de apareamiento A1. El uso de los marcadores moleculares mencionados en opinión de varios expertos aún no es confiable, por lo que sería conveniente hacer nuevos estudios sobre las poblaciones de tizón en Bolivia, que permitan confirmar la presencia y/o ausencia del tipo de apareamiento A1.

Se confirmó que las razas de tizón encontradas en las zonas de Morochata, Colomi y Anzaldo en Cochabamba, Tarabuco y Lampacillos en Chuquisaca, Betanzos en Potosí y Colquencha en La Paz, son complejas (Plata, 1998; Colque et al., 2011; Gabriel et al., 2018) y de alta variabilidad genética con un promedio de siete genes de virulencia. Los genes de virulencia más frecuentes encontrados fueron el 1, 3, 7, $10 \mathrm{y} 11$, menos frecuentes el 2, 4, y 6, y poco frecuentes el 5,8, y 9 . No se encontró nuevas poblaciones de tizón producto de recombinación sexual; sin embargo, estudios realizados por Gomez-Alpizar et al. (2007) en mitocondrias y genes nucleares de $P$. infestans de diferentes aislamientos de México, Perú, Ecuador, Bolivia, Brasil, Costa Rica, México, Estados Unidos e Irlanda, reportaron que el centro de origen de este patógeno podría estar en Sur América, particularmente en Bolivia y Ecuador.

Respecto al ciclo de la enfermedad, el tizón se desarrolla y esporula en condiciones de alta humedad (neblina o precipitación), produciéndose así el inóculo primario. Una vez realizada la infección primaria, la diseminación ocurre rápidamente por medio de los esporangios que a su vez liberan zoosporas que son transportadas por el 
agua y por el viento, infectando hojas de plantas sanas. Luego de un periodo de incubación de solo tres a cuatro días en las plantas infectadas, se forman nuevas zoosporas que constituyen el inóculo secundario que diseminará la enfermedad en la misma parcela y las adyacentes, constituyendo el ciclo secundario de la enfermedad que se repite varias veces durante el periodo del cultivo (Cooke et al., 2011). La infección de los tubérculos se produce cuando la lluvia transporta a los esporangios de las hojas y tallos hacia el suelo. Los tubérculos pueden podrirse a consecuencia de una infección secundaria causada por otros patógenos.

El ciclo biológico del patógeno y la intensidad de infección del tizón tardío de la papa varía según las condiciones ambientales, definiendo zonas altamente propicias para su desarrollo como otras que no son tan óptimas para el desarrollo del tizón (Cooke et al., 2011). En base a este criterio, se identificaron dos sitios contrastantes de la Figura 1, una zona muy tizonera ubicada al norte del mapa de cultivo (Irupana) y otra no muy tizonera al sud del mapa (Iscayachi), para estos sitios se realizó un análisis climático en base a temperaturas y precipitaciones mensuales históricas.

La zona muy tizonera en Irupana es definida por una precipitación promedio de $816 \mathrm{~mm}$ con una temperatura promedio de $15.6{ }^{\circ} \mathrm{C}$, en cambio la zona no muy tizonera en Iscayachi, está definida por $646 \mathrm{~mm}$ de precipitación y una temperatura promedio de $16.5{ }^{\circ} \mathrm{C}$ (Figuras 2 A y 2B). Resultados similares se presentan cuando se agrupan los promedios de todos los sitios para temperatura y precipitación (datos no mostrados), así, las zonas muy tizoneras están definidas por precipitaciones acumuladas entre $650-1700 \mathrm{~mm}$ y temperaturas promedio de $18^{\circ} \mathrm{C}$; en las zonas no muy tizoneras las precipitaciones son menores a los 650 mm con temperaturas mínimas mayores a $\operatorname{los} 11^{\circ} \mathrm{C}$.

En base a la Figura 2, muestra que las condiciones de humedad debido a las precipitaciones son las que definen principalmente la aptitud para acoger al patógeno (Figura 2A), en cambio ni las temperaturas promedio (datos no mostrados) ni las temperaturas máximas (Figura 2C) no definen claramente el hábitat propicio para el tizón. En cambio, de acuerdo a la Figura 2B, mientras más elevada sea la temperatura mínima (mayor a $10^{\circ} \mathrm{C}$ ), éste parece ser el umbral térmico límite para el desarrollo del tizón en Bolivia. Henfling (1987) indica que la temperatura más favorable para el desarrollo del hongo (micelio, esporangios) son los $21^{\circ} \mathrm{C}$. Sin embargo, temperaturas entre $\operatorname{los} 0$ a $28^{\circ} \mathrm{C}$ pueden permitir la supervivencia del hongo en tejidos hospedantes. 
A

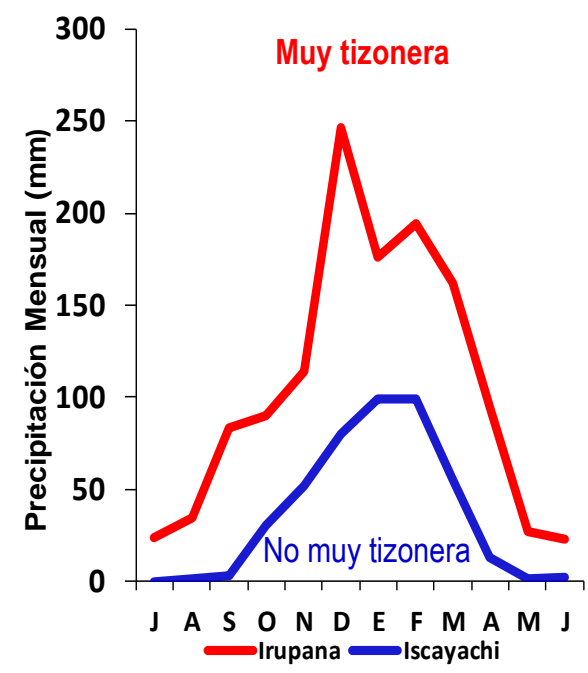

B

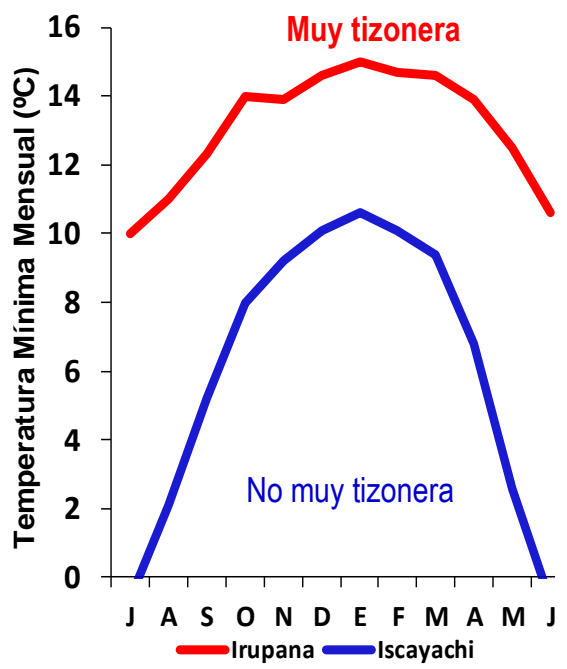

C

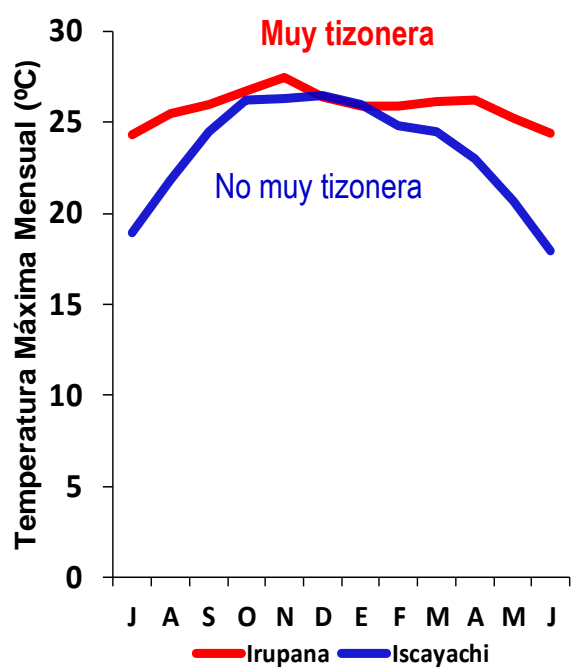

Figura 2. Promedios mensuales de precipitación (A), temperatura mínima mensual (B) y temperatura máxima mensual $(\mathrm{C})$ en una zona muy tizonera en localidad de Irupana y una zona no muy tizonera en la localidad de Iscayachi (elaborado por el Dr. Bruno Condorí).

La Figura 2, muestra las zonas muy tizoneras (caso Irupana), donde las temperaturas mínimas mensuales no tan extremas (mayores a $10^{\circ} \mathrm{C}$ ) y precipitaciones elevadas $(800 \mathrm{~mm}$ acumulado), el ataque de tizón se desarrolla y se propaga en forma más rápida favoreciendo el ciclo de la enfermedad. En las zonas no muy tizoneras (caso Iscayachi), temperaturas mínimas mensuales extremas (menores a $10^{\circ} \mathrm{C}$ ) y bajas precipitaciones (menores a los $650 \mathrm{~mm}$ acumulados) generan condiciones desfavorables para la enfermedad pudiendo prolongar o interrumpir temporalmente el ciclo. Así mismo, las diferencias de temperaturas máximas mensuales, aparentemente no definen claramente las diferencias entre ambas zonas. Estos patrones climáticos se aproximan a aquellas aseveraciones de Fernández-Northcote et al., (1999), permitiendo finalmente inferir que temperaturas mínimas no extremas (mayores a los $10^{\circ} \mathrm{C}$ ), requieren de alta humedad para la producción de zoosporangios, liberación de zoosporas y penetración al tejido vegetal.

Basados en el clima y la biológica del tizón, varios modelos de predicción del desarrollo de la enfermedad han sido generados, validados y puestos en práctica en los Estados Unidos de América y Europa, como herramientas de apoyo en la toma de decisiones para la aplicación de fungicidas. En Latinoamérica, la modelación de la enfermedad ha sido validada por Juarez et al. (2001) y Andrade Piedra et al., (2005) y reportados en Condori et al., (2016). Los modelos desarrollados permiten el uso racional de fungicidas, regulando la frecuencia de aplicación y evitando aspersiones innecesarias, éstos se basan en registros de humedad relativa, temperatura y precipitación, los cuales se analizan en un ordenador para dar a conocer la acción a tomar. Entre los modelos que predicen la ocurrencia de tizón podemos citar al Sistema CASTOR, BLITECAST, SIMCAST, NEGFRY y 
LATEBLIGHT (Juarez et al., 2001 y Andrade Piedra et al., 2005).

\section{Impacto del tizón tardío en la economía y seguridad alimentaria}

La papa es un cultivo de importancia en la seguridad alimentaria para la población de Bolivia. Para más de 130 mil familias de pequeños agricultores que constituyen entre el 30 al $40 \%$ del total de campesinos del país, la papa constituye la principal fuente de alimentación e ingresos. En su gran mayoría, los agricultores son de bajos recursos económicos y la superficie que utilizan no es mayor de una hectárea. El consumo per cápita esta entre 43 a 83 kg/año (Zeballos et al., 2009). Cerca de 130 mil ha son dedicadas al cultivo de la papa, con un rendimiento promedio en los Andes Bolivianos de $5 \mathrm{t} / \mathrm{ha}$, mientras que el mundial es de $14 \mathrm{t} / \mathrm{ha}$ y de $26 \mathrm{t} / \mathrm{ha}$ en los países desarrollados (Zeballos et al., 2009).

En términos económicos, el tizón es una de las enfermedades más importantes del cultivo de la papa. Se estima que en Bolivia más de 40 mil familias de agricultores paperos son afectados por el tizón. En las 20 mil ha de papa afectadas, la enfermedad ocasiona al presente una pérdida directa de alrededor de \$US 30 millones/año (Fernández-Northcore et al., 2009). La mayor parte del área afectada está en regiones productoras de semilla que actualmente sólo cubren el 5\% de las necesidades mínimas nacionales de semilla de calidad. Esta pérdida indirecta que ocasiona la enfermedad, magnifica la importancia del tizón en Bolivia como un factor limitante en la producción y productividad del cultivo de papa, el cultivo más importante en la economía agrícola del país.

Como consecuencia del tizón y la falta de conocimientos para una estrategia de control químico, el agricultor desarrolló una cultura de evasión de la enfermedad ya sea en el tiempo, mediante la utilización de otras épocas de siembra en que no se presenta la enfermedad o se presenta con más irregularidad, o en el espacio, cultivando en las épocas de mayor incidencia del tizón, sembrando en las partes de mayor altitud (más de 3400 msnm) donde las temperaturas más bajas (temperaturas mínimas menores a $10^{\circ} \mathrm{C}$ ) no son favorables para el desarrollo de la enfermedad. La cultura de la escapatoria a la enfermedad implica una baja productividad del área bajo cultivo que no concuerda con la preocupación contemporánea de incrementar la productividad por razones medioambientales y de la necesidad alimentaria presente y futura (FernándezNorthcote et al., 2009)

En base a la información de la distribución de $P$. infestans para Bolivia presentada en la Figura 1, se analizó los ambientes climáticos más favorables para la presencia del tizón en diferentes nichos ecológicos en un escenario actual (histórico) y un escenario con proyección futura al 2050. La modelación espacial climática de presencia de especies por nicho ecológico está descrita detalladamente en Patiño et al., (2008). Producto del anterior análisis (Figura 3), cuando comparamos las superficies para presencia de tizón en un escenario actual (Figura 3A) y un escenario futuro al 2050 (Figura 3B), se advierte que la superficie potencial para acoger al tizón en el futuro se incrementará en al menos $17 \%$ respecto a la superficie actual, es decir la presencia de tizón en parcelas productivas con cambio climático al 2050 podría alcanzar a 30 mil hectáreas más con características de ser infectadas con tizón. De otra parte, se advierte que nuevos nichos climáticos para el tizón se habilitarían en zonas más altas (Figura 
3C) especialmente en la parte norte de la cordillera Oriental de los Andes al Norte
del
del Lago
Titicaca
(Figura
$3)$.
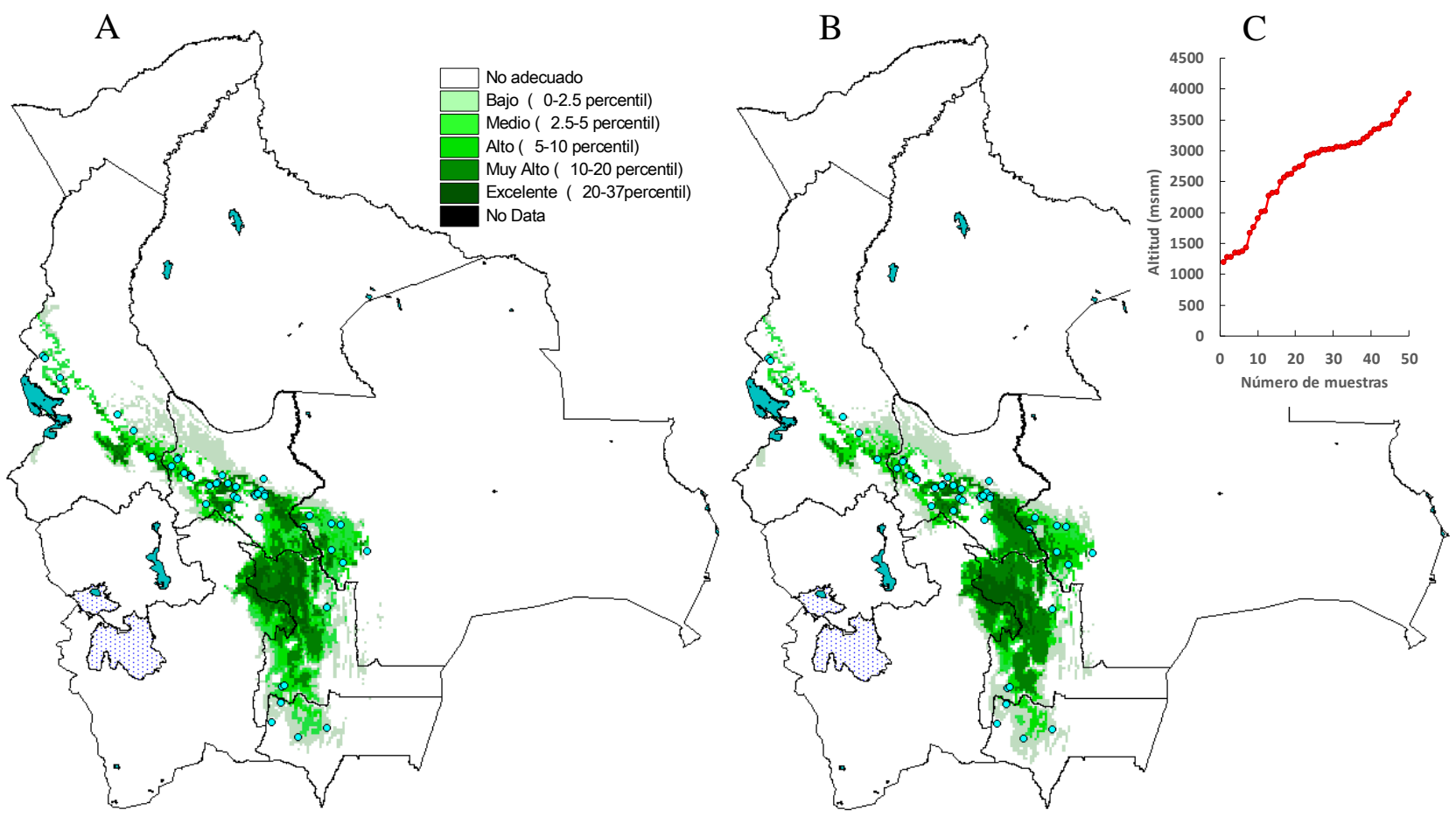

Figura 3. Distribución de P. infestans en escenario actual (A) y escenario futuro al 2050 (B) en Bolivia. Altitud en msnm de las muestras de tizón colectadas (C) descritas en los estudios en Bolivia. Elaboración propia.

El probable ascenso de la presencia del patógeno a zonas más elevadas (mayores a $4000 \mathrm{msnm}$ ) tendría un crucial impacto debido a que en las zonas altas se hallan las zonas semilleras de papa de calidad o certificada, si el tizón logra adaptarse a estas nuevas condiciones ambientales, sería un peligro mucho mayor debido a las pérdidas que ocasionaría en la producción de semilla de calidad, pero aún más, habría la posibilidad de que mediante el tubérculo semilla sea distribuida la enfermedad, agravando el problema de dispersión e infestación del tizón hacia nuevas zonas. En la actualidad, ya se ha visto síntomas de tizón en la comunidad de Cariquina Grande a más de 4000 msnm aspecto no visto a la fecha en base a los testimonios vertidos por los agricultores, aparentemente existen años que aparecen y otros no, se cree que para su aparición se combinen ciertas condiciones climáticas que facilitan o perjudican el ciclo biológico del tizón.

\section{Prácticas con adaptación relacionada con el manejo integrado del Tizón}

Desde 1992 PROINPA investigó y desarrollado estrategias para el control del tizón tanto en cultivares susceptibles y para complementar la resistencia genética de los cultivares disponibles en el país. La estrategia de PROINPA mostró ser efectiva y eficiente para el control del tizón, utilizando menor cantidad de 
fungicidas, logrando mayores rendimientos $(45 \%$ más) y mayores beneficios económicos para el agricultor.

Al presente estas estrategias están en una fase de transferencia y difusión como componentes de un manejo integrado del tizón sumados a los conocimientos tradicionales (Fernández-Northocte et al., 2009), es así que los agricultores no cuentan con estaciones meteorológicas, pero reconocen y asocian que la presencia de noches lluviosas, días soleados y neblina significa presencia del tizón, y basados en esta experiencia toman decisiones para realizar las aplicaciones de fungicidas.

Con el fin de evitar o disminuir las pérdidas ocasionadas por esta enfermedad, PROINPA desarrolló una estrategia de manejo integrado del tizón, que reduce costos, protege la salud del agricultor y representa menor daño para el medio ambiente. El manejo integrado del tizón incluye varios componentes como los siguientes:

Prácticas culturales, durante la época de siembra, se deberá realizar la selección de la parcela, eliminación de plantas voluntarias o k'ipas, selección de cultivares en función a su resistencia, utilización de semilla sana, distanciamiento adecuado entre plantas y surcos, aporque alto, reducción del tránsito a través del campo, corte del follaje, evitar la cosecha bajo condiciones húmedas y almacenar solo tubérculos sanos.

Resistencia sistemática inducida, una tecnología que PROINPA está desarrollando se basa en el concepto de la Resistencia Sistémica Inducida, que se refiere al incremento en la resistencia de una planta hacia los patógenos cuando es tratada con microorganismos (naturales del suelo), provocando una protección sistémica de toda la planta, contra una gama de enfermedades causadas por hongos y bacterias. Entre estos microorganismos, se tiene a las bacterias del género Bacillus (B. subtilis y B. amyloliquefasciens) (Navia et al., 2019).

Cultivares resistentes, el programa de mejoramiento genético de papa de PROINPA obtuvo nuevos cultivares con resistencia horizontal (resistencia residual) al tizón, entre ellas: Robusta, Jaspe India, Puka Huaycha, Aurora, Puyjuni Imilla, Palta Chola, Jatun Puka, etc. (Gabriel, 2010; Gabriel et al., 2011). El uso de cultivares mejorados con resistencia horizontal o poligénica, es la alternativa de control del tizón más conveniente para los agricultores, la incidencia y severidad de la enfermedad es menor, se reduce el número de aplicaciones de fungicidas y/o biofungicidas hasta uno o dos por ciclo de cultivo, se reduce el costo de control, se preserva la salud del agricultor y el medioambiente.

Disposiciones normativas, un mejor manejo integrado del tizón se realizará cuando los agricultores de una determinada zona se comprometan a una acción coordinada para ejecutar cada uno de los componentes del manejo integrado. El manejo integrado del tizón es menos efectivo si un agricultor lo practica y su vecino no. La durabilidad de la resistencia de una variedad será de un mayor número de años si se coordina su utilización en el espacio y en el tiempo (Gandarillas y Ortuño, 2009).

Manejo ecológico, se basa en el uso eficiente de biofungicidas como el Fungitop o la menor cantidad posible de fungicidas químicos (http://www.biotopbolivia.org/bt/index.ph p/es/nosotros). Está diseñado para los cultivares susceptibles más difundidas en 
el país como Huaycha, Sani Imilla y Desirée, y para cultivares resistentes como Runa, Toralapa, Musuj, Robusta, Jaspe, India, Puka Huaycha, Aurora, Puyjuni Imilla, Palta Chola, Jatun Puka, etc. (Gabriel et al., 2011)

En los cultivos resistentes, el inicio y desarrollo de la enfermedad es mucho más lento que en los cultivares susceptibles. Este hecho permite integrar el uso de cultivares resistentes con un control con biofungicida y/o fungicidas que empiece cuando se observan los primeros síntomas de la enfermedad. Los biofungicidas pueden reemplazar a los fungicidas de contacto (Navia et al., 2019).

\section{Estrategia de manejo ecológico}

Aplicación preventiva de los biofungicidas o fungicidas a los 10 días después del $80 \%$ de emergencia, es decir antes de que aparezca el tizón. La frecuencia de aplicación debe ser de 7 a 14 días según las condiciones climáticas, muy favorables o poco favorables respectivamente. Alternancia de un producto sistémico y de contacto y la no utilización del fungicida sistémico en más de tres oportunidades (FernándezNorthcote et al., 2009).

Es muy importante que la primera aplicación del fungicida se realice en forma preventiva, antes de que aparezcan los primeros síntomas de la enfermedad (Fernández-Northcote et al., 2009).

En una zona papera de clima muy tizonera se recomienda que las aplicaciones comiencen con un fungicida sistémico (Fernández-Northcote et al., 2009). En una zona papera de clima no muy tizonera las aplicaciones pueden comenzar con un eco-fungicida $\mathrm{o}$ fungicidas de contacto.

\section{Prácticas con adaptación relacionadas al manejo integrado del tizón}

Debido a los retrasos de las lluvias, los agricultores también están retrasando las siembras, lo cual ocasiona que los cultivares susceptibles en sus fases tempranas de desarrollo sean favorables para el ataque del patógeno. Para prevenir pérdidas drásticas se debe recomendar seguir la estrategia para cultivares susceptibles.

Considerando en las zonas próximas al Lago Titicaca, donde los agricultores desconocen la enfermedad, podría haber erosión genética de cultivares nativas por desconocimiento del manejo de la enfermedad y también podrían ocasionar fácilmente resistencia a fungicidas.

Una alternativa a este problema es el uso de cultivares resistentes, en estos ensayos también se debe considerar algunas prácticas culturales como ser densidades de siembra bajas, aporques oportunos, deshierbes y eliminación de plantas voluntarias o k'ipas. A su vez recomendar el uso de la estrategia de cultivares resistentes.

El desarrollo de cultivares precoces con cierta tolerancia a sequía, permitirían mantener las fechas de las siembras.

Monitoreo constante: de las zonas tradicionalmente tizoneras, pocas tizoneras y zonas de posible riesgo, permitirá ajustar o desarrollar nuevas herramientas para el manejo de la enfermedad.

Se debe actualizar en las diferentes zonas que está ocurriendo con los cultivares nativos, el uso indiscriminado de plaguicidas, resistencia, incremento en el número de aplicaciones, desplazamiento del cultivo a zonas más altas o reemplazo del cultivo por otros. 


\section{Conflictos de intereses}

Los autores declaran que presente documento no tiene conflictos de intereses.

\section{Referencias citadas}

Andrade-Piedra, J.L.; Hijmans, R.J.; Juárez, H.S.; Forbes, G.A.; Shtienberg, D.; and Fry, W.E. (2005). Simulation of Potato Late Blight in the Andes. II: Validation of the LATEBLIGHT Model. Phytopathology (2005) Volume: 95, Issue: 10, Pages: 1200-1208.

Coca-Morante, M. (2012). Tizón tardío de la papa causado por Phytophthora infestans, en Bolivia. Boletín técnico 6 (5): 4

Coca-Morante, M.; M. Tolin-Tordoya. (2013). The Potato late blight caused by Phytophthora infestans (Mont.) de Bary as selection factor of phurejas potatoes (Solanum phureja Juz. and Buk.) in Endemic Areas of the Bolivian Andes. Am. J. Plant. Sci. 4: 53-58.

Colque, C.; E. Fernández-Northcote; G. Plata; J. Gabriel. (2011). Resistencia a aislamientos de tizón en especies silvestres $\mathrm{y}$ en variedades nativas $\mathrm{y}$ comerciales de papa. Revista de Agricultura 50: 18-26.

Condori, B.; De La Casa, A.; Adalton Mazetti, F.; Rogério Peres, S.; Olarte Mantilla, S.; Jerez Mompies, E.; Clavijo Ponce, N.; Rodriguez, D.; Gómez Benitez, B.; Trebejo, I.; Vilaro, F.; García, C.; Sarmiento, L.; Rodriguez Baide, J.; Van Den Berg, M. (2016). Modelación de la papa en Latinoamérica: Estado del arte y base de datos para parametrización; Luxembourg: Publications Office of the European Union; EUR 28396 ES; doi:10.2788/520167.
Cooke, L.R.; Schepers, H.T.A.M.; Hermansen, A.; Bain, R.A.; Bradshaw, N.J.; Ritchie, F.; Shaw, D.S.; Evenhuis, A.; Kessel, G.J.T.; Wander, J.G.N.; Andersson, B.; Hansen, J.G.; Hannukkala, A.; Nærstad, R.; Nielsen, B.J. (2011). Epidemiology and integrated control of potato late blight in Europe. Potato Research 54: 183-22.

Fernández- Northcote, E.; O. Navia; A. Gandarillas. (1999). Bases de las estrategias de control químico de tizón tardío de la papa desarrolladas por PROINPA en Bolivia. Revista Latinoamericana de la Papa 1 (11): 1-25.

Gabriel, J. (2010). Documento marco: Estrategias y perspectivas del mejoramiento genético de papa (Solanum tuberosum L.) en Bolivia. Fundación PROINPA, Cochabamba, Bolivia. 60 p.

Gabriel, J.; Pereira, R.; Gandarillas, A. (2011). Catálogo de nuevas variedades de papa en Bolivia. Fundación PROINPA. Cochabamba, Bolivia. 55 p.

Gabriel, J.; Coca, A.; Plata, G.; Parlevliet, J.E. (2007). Characterization of the resistance to Phytophthora infestans in local potato cultivars in Bolivia. Euphytica 153: 321-328.

Gabriel, J.; Magne. J.; Veramendi, S. Angulo, A.; Rodriguez, F.; Bejarano, C.; Esprella, R.; Manobanda, M. (2018). El tizón de la papa (Phytophthora infestans) en Bolivia: Retos y oportunidades. Revista Latinoamericana de la Papa 22 (1): 80 .

Gabriel, J.; Plata, G.; Cadima, X.; Franco, J. (2013). Solanum phureja Juz et Buk.: inexhaustible source of genetic resistance to potato late blight [Phytophthora infestans (Mont.) de Bary]. Revista latinoamericana de la Papa 17 (2): 132 142. 
Gandarillas, A.; Ortuño, N. (Ed.) (2009). Compendio de enfermedades. Insectos, nematodos $y$ factores abióticos que afectan el cultivo de papa en Bolivia. Fundación PROINPA, Cochabamba, Bolivia. 178 p.

Gómez-Alpizar, L; I. Carbone; J.B. Ristaino. (2007). An Andean origin of Phytophthora infestans inferred from mitochondrial and nuclear gene genealogies. PNAS 104 (9): 3306-3311.

Juarez, H. S; Avila, L. M.; Hijmans, R. (2001). Late blight forecasting models and de Castor 2.0 Software. Pages in: Procedings of de International Worshop on Complementing Resistance to Late Blight (Phytopphthora infestans) in the Andes. February 13-16, 2001. Cochabamba, Bolivia. Gilb Latin American Workshops 1. E.N. FernandezNorthcote, ed. International Potato center, Lima, Perú.

Judelson, H.S. (1996). Chromosomal heteromorphism linked to the mating type locus of the oomycete Phytophthora infestans. Mol Gen Genet 252: 155-161.

Navia, O; Plata, G.; Equise, H.; Gabriel, J.; Gandarillas, A. (2009). Tizón tardío (Phytophthora infestans). Páginas 64-71 in Antonio Gandarillas y Noel Ortuño Eds.: Compendio de enfermedades, insectos, nemátodos y factores abióticos que afectan el cultivo de papa en Bolivia. Fundación PROINPA Ed., Cochabamba, Bolivia.

Navia, O.; Gandarillas, A.; Ortuño, N.; Meneces, E.; Franco, J. (25 de mayo de
2019). Tizón de la papa (Phytopthora infestans) y agricultura sostenible: Integración de rsistencia sistémica inducida y estrategias de manejo integrado, Fundación PROINPA. Disponible en http://C:/Users/Vinicio\%20Vel\%C3\%A1 squez/Downloads/Oscar\%20Navia_tizon \%20papa\%20(1).pdf

Nieva, B. (2012). Caracterización de aislados de Phytophthora infestans. Memoria de prácticas tuteladas. Neiker Tecnalia, Vitoria-Gasteiz, España.

Patiño, F; Condori, B.; Segales, L.; Mamani, A.; y Cadima, X. (2008). Atlas de especies silvestres y cultivadas de papa en Bolivia. VBRFMA - BIOVERSITY 2008. La Paz, Bolivia. 100 p.

Pérez, W.; Forbes, G. (2008). Manual Técnico: El tizón tardío de la papa. Centro Internacional de la Papa. Lima, Perú.

Plata, G. (1998). Fenotipos de virulencia en Morochata y tipo sexual de apareamiento en Bolivia de Phytophthora infestans que afectan el cultivo de la papa (Solanum tuberosum). Tesis de grado para obtener el título de Ingeniero Agrónomo. Universidad Mayor de San Simón - UMSS. Cochabamba-Bolivia. $193 \mathrm{p}$.

Zeballos, H.; Balderrama, E.; Condori, B.; Blajos, J. (2009). Economía de la papa en Bolivia (1998-2007). Fundación PROINPA, Cochabamba, Bolivia. 